This is an Authors' Accepted Manuscript of a paper forthcoming for publication in the book Teaching with Sociological Imagination in Higher \& Further Education: Contexts, Pedagogies, Reflections, edited by Christopher R. Matthews, Ursula Edgington and Alex Channon, copyright Springer, 2018, ISBN: 9789811067242.

\title{
Moving Lessons: Teaching Sociology through Embodied Learning in the HE Classroom
}

\author{
Alex Channon \\ School of Sport and Service Management, University of Brighton, Eastbourne, UK \\ Christopher R. Matthews \\ School of Science and Technology, Nottingham Trent University, Nottingham, UK \\ Anastasiya Khomutova \\ School of Sport and Service Management, University of Brighton, Eastbourne, UK \\ Corresponding Author: \\ Dr. Alex Channon, School of Sport and Service Management, University of Brighton, Eastbourne, \\ UK \\ Tel: (+44)1273643746 \\ Email: a.channon@brighton.ac.uk
}


Alex Channon, University of Brighton, UK.

Christopher R. Matthews, University of Brighton, UK.

Anastasiya Khomutova, University of Brighton, UK.

\section{Abstract}

This chapter outlines an approach to classroom teaching that makes use of physical movement alongside more traditional lecturing methods when delivering lessons on abstract theoretical material. It develops the notion of embodied learning as a 'physical metaphor', outlining some examples of this practice that we have used in our recent work with a class of first year undergraduates. We argue that conceptualising students as embodied subjects, whose capacity to learn extends through and beyond their physical selves, educators are able to enhance classroom delivery by diversifying teaching activities and creating opportunities for enjoyable and memorable learning experiences. We advocate the reflexive, contextually-sensitive and level-appropriate use of this method, arguing that despite some limitations it can animate students' understanding of academic ideas in uniquely personalised ways.

\section{Introduction: Self- and Student-Centeredness in HE Teaching}

As early career academics starting our HE teaching careers at three different 'post-92' UK institutions ${ }^{1}$ during the early-mid 2010s, our initial experiences as university educators followed similar, somewhat paradoxical paths. Fresh from our respective PhD programmes, we entered our first lecturing posts on the back of several years of developing, and then proving, our ability to understand and communicate complex academic ideas largely through the medium of written prose and academic oratory. Herein, we built our self-concept as academics on how well we could perform 'at the sharp end' of intellectual discourse, both as an end in itself, but also as an indicator of our likely future successes in the vital games of grant-winning and research dissemination. Could we add those all-important lines to our CVs by publishing papers in reputable, peer-reviewed journals? Could we deliver bullet-proof academic presentations in just 15 minutes to a critical audience of our peers? Could we hold our own in debates on Judith Butler's feminism, or the importance of reading Norbert Elias in German? Ultimately, could we prove that we were good enough for academia?

1 Post-92 institutions are those granted the ability to award university degrees after 1992, many of which previously existed as technical colleges beforehand. Although there are certainly exceptions, they are generally ranked lower on most national league tables than comparable, older institutions; they typically offer courses that are vocational in nature; and they generally tend to place more importance on income generated through teaching than research. 
Although central to the eventual, successful completion of our theses and viva exams, this side of our PhD experiences did little to prepare us to enter a world where the learning of undergraduate students would be of utmost importance in our daily working lives. Encouraged over the course of several years of undergraduate and postgraduate study to view our work as an individual performance upon which we would be evaluated, we operated in ways which placed ourselves at the centre of what we did. How well we understood the (often unfamiliar) topics we would be required to teach; how slick our multimedia Prezi or PowerPoint presentations could be; and how well we could 'stand and deliver' to a crowded lecture theatre became the defining concerns of those early months on the job. Although we worked in a HE sector saturated with rhetoric around being 'student-centred', our long-habituated focus on the self was not helped by the evaluative climate shaped by probationary periods, mentorship arrangements, and individualised student assessment of the modules we taught. Thus, as we transitioned from research-focused to teachingheavy roles, the matter of questioning 'how good we were' as academics remained central to our day-to-day work.

While this did not mean that we were poor teachers at this time, it nevertheless provided the starting point for an important early lesson in what it means to be genuinely 'student-centred', in practice rather than simply in theory. In this sense, it was not the fact that we were reflective on our performances that mattered, but rather the criteria against which we were initially given to evaluating them. Particularly, this revolved around a failure to foreground what it was that our audiences in the lecture hall actually wanted and needed, focusing instead on our own preconceived ideas about what might count as a successful lesson or module delivery. In this sense, it was not unsurprising to find students questioning the relevance of the theoretical material we taught, or simply struggling to focus on the abstract ideas we were presenting to them through a mode of teaching with which we ourselves were most familiar. As a consequence, the knowledge and academic skillset we were hoping to impart to our students were getting lost in translation; our undergraduates were simply not ready for a method of learning built largely upon the expectations and habituated practices of post-doctoral researchers.

Subsequently, following our early experiences with both formal and informal student feedback, we came to realise that our initial perspectives on what counted as good academic work had left us somewhat out of step with the young people with - and for whom - we were now working. Questioning the purpose and direction of the HE experience from our students' point of view, we found ourselves able to reflect differently on our potential as educators. While we wanted the students to be exposed to rigorous, critical and comprehensive intellectual arguments, the students wanted to learn something enjoyable that could hold their interest and attention. While we cared about research-informed teaching, driven by new developments in our respective fields, the students wanted to learn things that held relevance for them, either personally or with respect to their career aspirations. And while we wanted to discuss those things in class that we cared deeply about, our students wanted us to show them why they should care about these things, too. Although at first it was tempting to view such differences as being oppositional in some way, asking how we might marry up such apparently competing goals led our professional reflection in some intriguing directions. Whatever the answers we might arrive at, as the professionals in whom our undergraduates had at least partially invested their futures, we owed them such a place of prominence in our reflective processes and evolving pedagogical practices. 
Such recognition, of course, was timely in a context of increasing importance becoming attached to objective measures of 'student experience', like the UK's National Student Survey', along with other outcomes such as graduate 'employability', measured nationally in the UK by the Destination of Leavers from Higher Education survey ${ }^{3}$. However, unlike these quantified, dehumanising exercises that 'centralise' students as statistical entities, our realisation that students' needs and desires ought to figure centrally in our work was built upon the growing empathy formed within and through pedagogical relationships with young people. Thus, rather than reducing our work to a series of arbitrary concerns over 'key performance indicators' (employability; satisfaction; etc.), these issues prioritised the actual experiences of students, as illustrated to us through formal feedback mechanisms but also established through tutorial sessions and other informal chats around campus. We thereby re-focused our understanding of 'student experience' on the purposeful enhancement of students' learning and, most importantly of all, the development of their desire to learn.

Such fundamental concerns form the basis upon which we develop the rest of this chapter. While a great many topics for debate might arise from these statements and observations, we focus here on the issue of promoting students' engagement and enthusiasm for study, and our role in nurturing this as a means of better equipping them to develop vital graduate skills. More specifically, we argue that departing from normative expectations about university-level study as a disembodied, rational, purely cognitive activity can provide some answers to the question of reconciling the apparently competing visions of HE noted above. Such a departure is particularly important when considering the increasingly large number of students who arrive at university unprepared for the model of learning represented by what we might call the traditional, 'sit and listen, go and read' approach that we were, to varying degrees, exposed to ourselves - and which formed the primary means of our own learning (at doctorate level) immediately prior to entering the HE teaching profession.

In what follows then, we outline one particular method for accomplishing this goal - the use of embodied learning strategies within the HE classroom. We argue that this approach offers the potential to create enjoyable and memorable experiences that resonate well with our students' conceptions of engaging, effective, and ultimately 'satisfying' university education. As formal and informal feedback from our students have shown, such methods can be helpful in personalising learning and emphasising, to varying degrees, the relevance of conceptual material delivered in more abstract or discursive ways. As we hope to show, embodied approaches can accommodate critical intellectual sensibility and reflexive self-awareness, forming a pedagogically robust method of promoting student engagement and development within the context of the classroom itself, and thereby providing a genuine enhancement of the student experience of $\mathrm{HE}$ teaching.

2 See www.thestudentsurvey.com.

3 See www.hefce.ac.uk/lt/dlhe. 


\section{Moving Lessons: Learning through Moving}

Among physical educationists, the notion that physical activity can be a valuable medium for learning is a widely shared ideal. Indeed, that young people can effectively benefit in numerous and diverse ways (including the development of social skills, construction of moral frameworks, or even improvements in literacy and numeracy, etc.) through lessons built upon embodied learning is a core assumption of physical education. However, such a possibility is often overlooked outside of the discipline, where pernicious intellectual snobbery, built on the shaky foundations of Cartesian Dualism, persists in educational settings across many social contexts, prioritising the 'mental' over the 'physical' and wrongly assuming that 'never the twain shall meet' (see Hardman and Green, 2011). This has traditionally seen physical education classes receive short shrift in terms of schools' curriculum time and budgetary expenditure, with the PE teaching profession often dismissed as a role with little value beyond sport training or health management for primary- and secondary-age pupils' learning (Green, 2008).

Central to this general scepticism is the notion that bodily movement-based learning activities are only useful for enhancing pupils'/students' embodied competencies, with little to offer the development of 'the mind'. Such reasoning carries over into the HE context; in this sense, the use of physical activity in such fields as actor training, dance and performing arts, or sport coaching/pedagogy is common, focusing on students' developing physical skills and embodied knowledge, but movement rarely features as a medium for learning outside of such 'practical' contexts. However, our experience tells us that there are a number of ways in which physical movement in lectures and seminars can contribute positively towards students' critical, intellectual development; that is, 'moving lessons' can add value to more than just the most obviously embodied fields of learning.

This observation, of course, is not new in terms of existing theory and scholarship on embodied, or 'kinaesthetic' learning as a tool for formal educational pedagogy. An element of Gardner's influential (2006) notion of multiple intelligences, implicit within Kolb's (1984) typology of learning, and constituting one dimension of the popular VAK model (Dunn \& Dunn, 1992), among others, the kinaesthetic/bodily dimension of human learning is a well-established concept in educational scholarship. Likewise, a wide and expansive research base crossing fields including anthropology, psychology, sociology, and neuroscience demonstrate the fundamentally embodied nature of human subjects and by extension, their capacity to learn (e.g., Cromby, 2015; Crossley, 2006; Shapiro, 2014; Spatz, 2015). This makes clear that cognitive, affective and social dimensions of human experience should not be conceptualised in ways that separate them from the physical body, the conduit through which subjects interface with the world as they construct their understanding of it.

Despite such knowledge abounding across academic fields, embodied learning and the physical activities this might involve within the university classroom is very rarely discussed in practicaloriented textbooks on teaching and learning in HE (e.g., Brockbank and McGill, 2007; Dunne and Owen, 2013; Lea, 2015; Light, Cox and Calkins, 2009 - see Biggs and Tang, 2011 for a notable but very brief exception). This preserves the myth that education - and particularly 'higher' education is fundamentally premised upon techniques for developing student's disembodied mental capacities. Indeed, while 'keeping students active' is often cited as a meaningful pedagogical method in many 
such texts, and is a mantra we've often heard from professional development workshop facilitators and our own colleagues across multiple university departments, this is almost always noted with reference to some form of cognitive engagement in, for instance, group discussion or problem solving, without attention to the potential of physical activity for meeting learning goals.

Meanwhile, in some texts (e.g., Mortiboys, 2010), physical activity is mentioned purely with respect to behaviour management, and then only in passing and without any clear articulation of specific classroom methods, or attention to their more robust pedagogical applications. In others, discussion of the embodied dimensions of teaching are primarily associated with understanding the lecturer's body (e.g., Fry, Ketteridge and Marshall, 2015). Although discussing bodily techniques used when lecturing (such as voice projection, body language, etc.) or embodied differences between lecturers (such as sex/gender, ethnicity, etc.) is certainly worthwhile, foregrounding these important phenomena without also paying attention to the role of students as embodied agents in the learning process replicates the broader contextual problem outlined above regarding a lack of genuine student-centeredness in HE pedagogy.

In spite of this relative lack of attention in the extant 'how to' literature on HE teaching and learning, we argue that embodied methods can provide a uniquely rich opportunity to animate students' classroom experiences, bringing conceptual material 'to life' in potentially profound ways.

Recognising students as embodied subjects, 'moving lessons' prioritise physical interaction and experience, engaging students' kinaesthetic sense of themselves and others rather than depending solely on auditory and visual teaching methods. They can deploy students' own bodies as metaphorical or literal examples for illustrating conceptual ideas, thereby personalising learning in unique ways and adding a visceral sense of immanence to the abstract material being taught. And of course, they have the potential to be a lot of fun as well, helping keep students engaged, potentially making for more memorable classroom teaching and, in our view, constitute a more rewarding experience as lecturers (see Biggs and Tang, 2011).

Although there is plenty to unpack and critique within this position, it is not our intention in this chapter to contribute to or answer existing theorisations of embodiment and embodied learning in this field, but rather to share some examples of practical strategies that have been useful to us in our recent teaching of sociology. In particular, the stories we share below highlight the uses of embodied learning methods for animating conceptual lessons in the classroom, intended to provide some indication of how lessons involving physical movement can enrich student learning of abstract sociological concepts and intellectual skills.

\section{Physical Metaphors: Practical Examples of 'Moving Lessons'}

In what follows, we outline three separate but similar classroom activities that we have recently used towards these ends. It should be stressed that the activities discussed below are not designed towards developing physical skills or competencies, but rather providing a means for students to embody some aspects of the otherwise theoretical lessons being delivered, thereby coming to grasp conceptual material traditionally taught through only discursive or audio-visual methods. 
It is also worth noting that these sessions all took place with groups of students with whom we had spent a few weeks building up rapport beforehand, wherein we deliberately sought to construct our lectures as 'safe places' where students could and should explore challenging ideas in a respectful and supportive manner. The students were told from the outset that we would, at various points on the module, be 'moving them around' in class as a means of helping them learn, and that any student who felt uncomfortable or would not be able to take part should feel under no obligation to do so (points we return to briefly below). We begin with a simple, lecture-based exercise within a first year undergraduate session on the topic of 'social stratification'.

\section{Vignette 1: Embodying stratification}

One of the first ways in which we saw the power of movement in the lecture theatre was during a class that was designed to help students develop an understanding of the ways in which social processes can stratify people and groups into hierarchical relationships. Such a notion lends itself neatly to an embodied pedagogy whereby the physical group of students becomes a teaching device itself, and in so doing each student is provided with a vivid, physical illustration of a vital abstract idea. Following a discussion of the role that the media can play in normalising inequality by stigmatising certain bodies (those that are too fat, too old, etc.), Christopher set up an embodied learning task: "Right then, let's take this further and try to get a real grasp of how this process might work in practice. Everyone down to the front (of the lecture theatre)!"

As expected, this request was met with an initial lack of movement but with some encouragement from Christopher and Alex, the students made their way down the stairs towards the lectern, whiteboard and teaching paraphernalia that tended to be off-limits to them. Once in place, the students were instructed to line up in height order: "tallest on the left, shortest on the right". As approximately 100 bodies chaotically mingle around the front of the classroom, busily stratifying themselves, there is buzz of amusement; good-natured arguments break out among those of roughly even height. The novelty of moving around the lecture theatre clearly enthuses the majority of the students. Height rankings eventually achieved, Christopher shouts over the hubbub: "OK, so that was easy enough. Now... let's go by age. Oldest on the right, youngest on the left." With resigned smiles on their faces the mature students move off to the right, while the rest of the group start the process of figuring out each other's birth dates. Once lined up, the students curiously scan their peers, noting who is apparently older than whom.

The job now is to help the students take this 'moving lesson' and learn from it. Christopher returns to the earlier discussion of social stratification, highlighting the role played by the lecturers, standing in for 'society', in demanding that bodies ought to be ranked by these arbitrary characteristics:

"We've defined for you that height matters, that age matters, and that you should rank each other that way; think about how our society does this to us in other ways, like by sex, or race, or disability." We encourage reflection on how people are stratified by both visible characteristics (like height) but also invisible, often assumed ones (like age). At this, several students nod their comprehension. We return to the examples noted previously regarding the mass media, discussing how certain bodies are more visible and thus made to seem more valuable; and how such valuejudgements are made for us, and thrust upon us, by others. 
The next phase of the exercise begins; we instruct the students to form groups of five or six, and joke, "It's time to stratify based on ability, so let's hope you're feeling competitive!" The response is, again, a mixture of bemusement and mild excitement. Christopher pulls out a stopwatch and tells the students to prepare to take it in turns to individually do press-ups for 30 seconds each. Teams are instructed to keep score themselves and to encourage their teammates; the next few minutes are a frantic mix of physical (in)action, laughing, cheering, and cheating. Eventually, the exercise concludes: "Five, four, three, two, one, STOP!" The students are asked to report how many press-ups their team managed; a show of hands for successively greater ranges of totals reveals the two highest scoring teams.

We instruct the majority of students to make their way back to their seats, while the two winning groups wait anxiously at the front of the lecture theatre, now the centre of attention. Christopher pulls out some high-visibility vests and asks the students to put them on: "Right then, here we have them, the best of the best... Or are they? Nobody can do that many; this group must have cheated!" - a chorus of jeers from the theatre - "They must now wear their vests for the rest of the day so that everyone on campus knows that they can't be trusted! And this group? They did well - too well! They've spent so much time in the gym that they have not been keeping up with their reading for this module. They have to wear these vests all day so that all of campus knows they are going to fail!"

The students now sitting comfortably in their seats laugh at the situation their colleagues find themselves in. Christopher delivers this all in a manner that makes it clear that he is being facetious, stepping out of the performance in order to pull the activity together: "Right, so social processes don't just stratify us into different groups but they can put us into different hierarchies. We just did that using physical ability as a differentiator. And that's what the media images we talked about earlier do; they differentiate but can also stigmatise. I stigmatised those two groups by changing what their performances meant, by making it seem bad to be capable of something..." The lecture continues from this point, touching on the power of the media in framing actions of different social groups differently; the gendering of athletic success, the racializing of crime, and so on.

At the eventual close of this lecture, as with others, the students are encouraged to make notes on the lesson and to consider in groups their experiences of growing up and being caught up in such processes of stratification, reflecting on how their own bodies are often implicated in these processes. What we have sought to do here is personalise the teaching experience, in a way which not only requires active engagement, but also activates affective responses through the social interactions required of students, along with the ironically humorous inversion of physical hierarchies worked at the end. In so doing, we help students interpret and learn in a manner that can be personally resonant, clearly attached to the arbitrary positioning of their bodies within society. These aims are also borne out in the next example, which called for further interaction while underscoring two different conceptual lessons.

\section{Vignette 2: Socially-constructed salsa}

By halfway through the term, implementing this move of ours towards frequent, purposeful, 'constructively aligned' embodied learning exercises had started proving tricky. At face value, 
choosing a 'guinea pig' module on the social scientific study of sport and fitness should provide ample opportunities for embodied learning, but some weekly topics were proving tough to pin down suitable tasks for. One week had us thinking of exercises we might use to illustrate how bodies their fitness, their shapes, their skill sets, and the meanings we attach to these things - are 'socially constructed'. We knew that, for our class of first year undergraduates, novel ways of illustrating this concept would be helpful, and no more so than one which put their own bodies' construction in the limelight. Examples from sport and fitness practices abound, but what could we do in the space of 45 minutes that was safe, inclusive, and met the learning objectives set during the lecture?

The answer came in the form of a salsa class (fig.1). Anastasiya had a history as a dancer, and followed Alex's lecture on social constructionist theory with a beginners' session sprung on unsuspecting students in the university gymnasium. The group's immediate response was divided; some quickly retreated to the rear of the hall, groaning in anticipation of their perceived, impending embarrassment, while others started cheering and shimmying, eager for the chance to show off their steps. This was a calculated move on our part; dance often has such an effect on young adults, and for students with no dance experience who'd taken a sport-based module, whose superior physical fitness and skill was likely otherwise a source of confidence and pride, this up-close encounter with their own ineptitude and discomfort would later demonstrate one of our intended learning outcomes well.

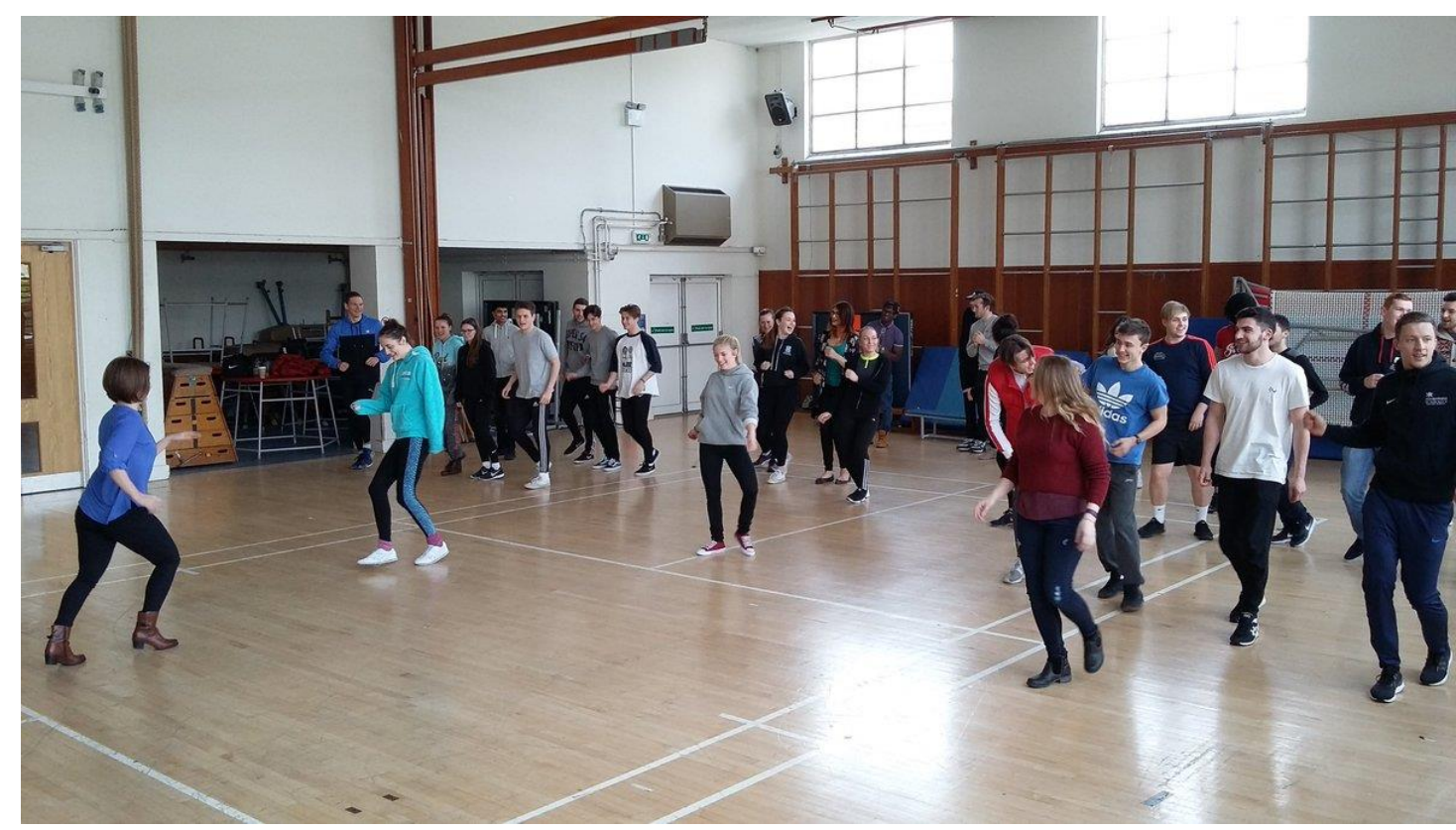

Fig.1 - Salsa dancing is unfamiliar to many young British students. Here, Anastasiya (left) and Alex use the activity to encourage reflection on how bodies, and their competencies, are socially constructed. Photo courtesy of Alex Channon.

The lesson began, Cuban music blaring, and students - some eagerly, others nervously - began copying the steps that Anastasiya, helped by some of the more able dancers in the group, set for them. After the basics were introduced, we picked individuals to step forward and show their moves - further light-hearted embarrassment, balanced with some enthusiastic peacocking. Then came the second phase of the lesson: "partner up!", Alex yelled over the music; "partner up with someone who's about the same size!". Predictably interpreted as someone of the same sex, students drifted 
into couples and waited. Anastasiya and Alex moved to the centre of the hall. "Ok," she began, "into the closed position - like this!"

As the two lecturers joined hands, placing a free hand to each other's backs, the jovial tension we had been hoping for grew. We knew we might be treading a fine line here, deliberately playing with notions of gender propriety, but our conceptual point was being set up perfectly. As students moved in time with their partners, we noticed that only a few of the boys were holding each other, most electing instead to stand off and mimic the position as they stepped in time to the music - a point to return to later, we knew. The last part of the exercise saw the students arranged in two circles, one inside the other, so that partners could quickly be swapped and moves practiced anew with unfamiliar others as one circle rotated around the other. As the session neared its end, we thanked and congratulated the group for their efforts and sat them down for a reflective discussion.

"So," Anastasiya asked, "who enjoyed that?" Plenty of hands went up. "And who didn't?" Some laughs, a few further hands. "Ok, but let's think about why not. We'll assume it wasn't my teaching" - a few further laughs - "so what's the problem with doing salsa?" The ensuing discussion pointed to a fear of public humiliation, a lack of practice, the awkwardness of the steps and of touching each other. "Plenty to unpack here, right?" asked Alex. "Let's start with the lack of practice - why haven't you practiced?" One young man - conveniently, a foreign student from a Latin American country chipped in: "well you guys don't do this much here. For me, I grew up with this. No problems for me!" Indeed, we elaborated. Our bodies' skills, and the confidence we take from them, are greatly shaped by culture. A female student eagerly interjected; "I know a lot of us girls have a dance background, so it's ok for us" - "Yeah", added another, "and it's not the same problem for girls to get over the touching thing, is it..."

Upon encouraging the students' reflective discourse on what had enabled or constrained their enjoyment of the class, the social construction of bodily action was clearly foregrounded, as students worked towards an appreciation of how their own abilities and dispositions had been shaped by cultural forces made visible through the salsa lesson. Gendered discourses stigmatising male dancers, and particularly male-male touch in quasi-sexualised encounters like paired dancing, were to thank for both the unfamiliarity many of the young men had towards the movements we taught, and also their initial awkwardness at being in hold. For the novice dancers, a gradual progression of their embodied ability - albeit minimal in the context of the lesson - was itself shown to be the effect of social relations between us the lecturers, and them the students. We had defined this physical enskilment as valuable and they, deferring to our authority in the context of the classroom, had therefore learned. And for those more expert dancers, the chance to demonstrate their bodies' capacities in an unfamiliar setting was shown to have served up opportunities to convert physical capital into a form of cultural capital, winning admiration of lecturers and peers alike. In this sense, an intellectual lesson was neatly depicted through an embodied activity built around a physical metaphor. The final vignette exemplifies this technique more directly, although used to develop students' understanding of academic writing rather than social theory. 


\section{Vignette 3: 'Writing is like fighting'}

As scholars with intellectual backgrounds in psychology and sociology who have been teaching on multi-disciplinary degree programmes within schools with diverse academic traditions, we have often noted that it falls to us and our colleagues to deliver not only social science-related content to students, but also to bear much of the responsibility for developing students' writing skills. Often done in either an informal, ad-hoc (in one-to-one, non-compulsory tutorial meetings) or a formal, post-hoc (by way of essay feedback) manner, there is often little purposeful time dedicated to teaching students how to write before they submit their first essays. For this reason, we decided to include a formal session specific to essay writing techniques to the module, and true to form, to deliver this through another 'moving lesson'.

Specifically, we decided to use a blend of embodied, multimedia, and interactive seminar learning in order to not only inject a deal of unpredictability and fun into this otherwise rather dry, technical subject, but also to provide multiple channels for developing and reinforcing our intended learning outcomes. Departing from the usually timetabled location, we split our large class into several smaller groups, booked a morning-long slot in the university gymnasium, and told our students to arrive for particular time-slots wearing light tracksuits and bringing a notepad and pen. We set up the room with a television screen, surrounded by wooden gym benches, in one corner, while the rest of the hall's floor was surfaced with martial arts training mats. Students arrived to find each of us wearing boxing gloves and training outfits, and while laughing off their amusement, set their bags and shoes to one side and gathered barefoot in the centre of the hall.

"Writing," declared Alex, "is like fighting. We're gonna teach you how to write an academic essay today, but we'll do it with a metaphor that'll hopefully be a bit more fun, a bit more memorable than your typical lesson." Between us, we go on to explain the central themes of the session, outlining our key learning outcome - that an academic essay is, first and foremost, an exercise in making an argument. We tell students to note down several key points that go into making such arguments the research, planning, and other background work; the importance of logically transitioning between disparate points in one's writing; the need to adopt persuasive language to help a reader accept one's case; the conclusive delivery of one's thesis; and so on. Then, we ask the group to stand: "put your notepads down, find a space, get warmed up!"

A few star jumps, some press-ups and a little light stretching later, we begin a boxing exercise after spelling out the first principle we wish the students to grasp. When fighting, we need to move our opponent's guard, luring them into a counter attack while we prepare them for our own scoring blows. Christopher demonstrates a simple technique with Alex as his target (fig.2) - two, three, four blows low on the body; as Alex repeatedly drops his guard to intercept, suddenly the fifth punch goes high, catching him on the temple. After a number of demonstrations, Christopher checks that the principle is clear. After clarifying the group's understanding, we move the exercise forward. 


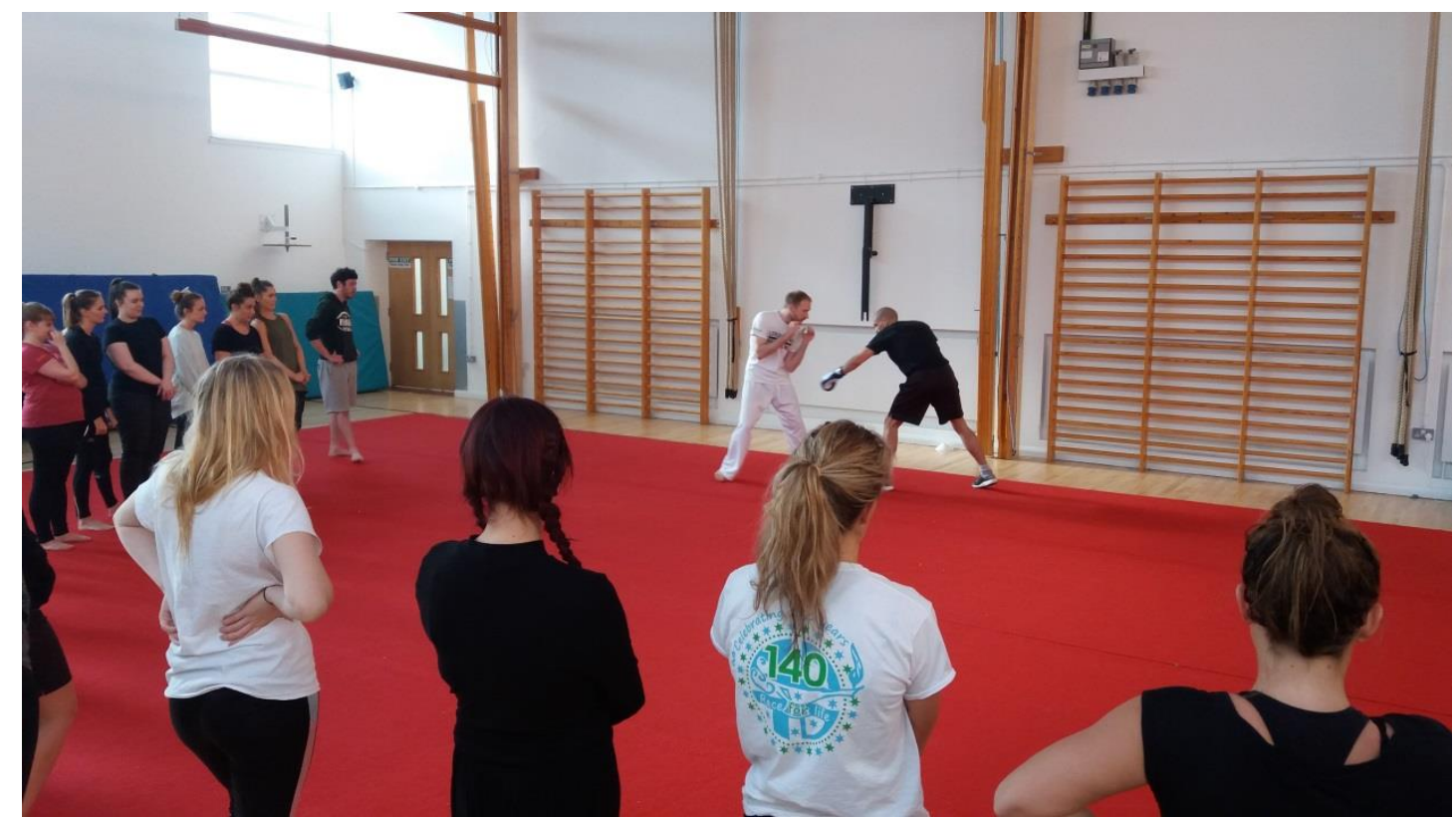

Fig.2 - Christopher's low jabs make Alex drop his guard, setting him up for the high right hook. With confident delivery and a little experience, this demonstration can be done at high speed for a more memorable, impactful lesson on forming a 'well-structured' argument. Photo courtesy of Anastasiya Khomutova.

To add a 'live' feel to the drill, but keep things safe for our novice students, we set them off on a game of 'foot-sparring' in size-matched pairs. Judging distance and foot speed, the students must attempt to step lightly on their opponents' feet while protecting their own (fig.3). Before long, an elaborate dance of feint and counter can be observed across the hall, as the sparring pairs grasp the tactics of responding to, pre-empting, and manipulating their opposite number's moves with careful timing and measured attacks. The game is good natured, with much laughter, but also a moderate level of competitive intensity, just enough to ensure the group's engagement.

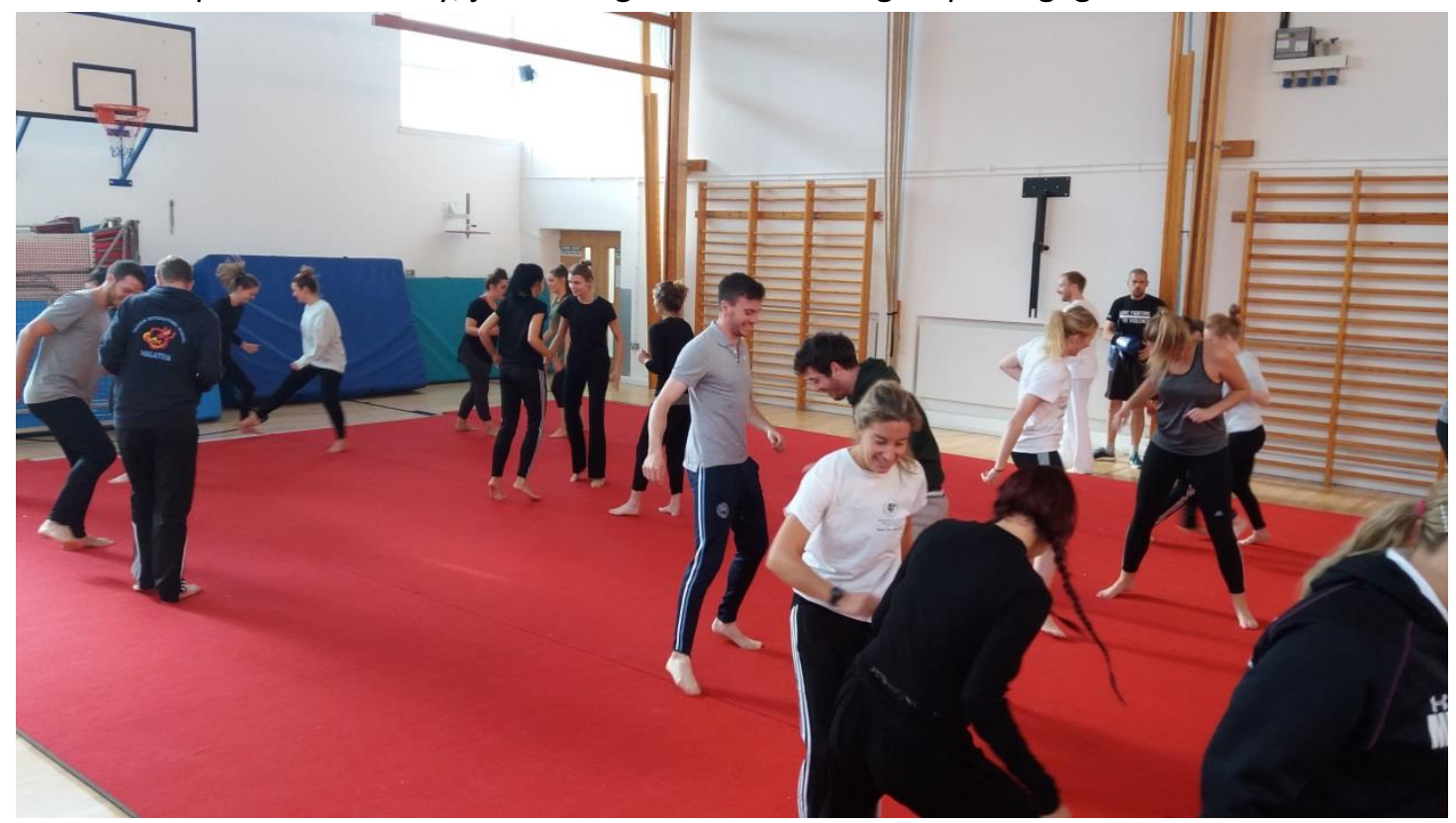

Fig.3 - Christopher and Alex supervise foot-sparring, as students learn that success depends on preempting opponents' counter attacks. This physical metaphor helps students grasp the importance of 
thinking through potential critiques of their written work, before preparing arguments accordingly. Photo courtesy of Anastasiya Khomutova.

Moments later, in full-group discussion once again, we reach our first conceptual point. The techniques we use as skilled fighters presuppose the existence of an opponent's defence, and to be effective they must find a way to overcome it. These techniques are rehearsed continually, to breed familiarity, and then put into effect against a live opponent. We ask the group, "what does this all tell us about writing?" Some answers are offered, and we work through students' ideas and encourage dialogue as the lesson begins to coalesce. When we write, we should first practice discussing our subject matter, preparing for the obvious critiques of our arguments, so that we might pre-empt them in our work. Ultimately, we must aim to deliver a case in a way that is most persuasive to a potentially sceptical reader in the final offering.

At this point, we sit the group down in their pairs. "By now," Christopher begins, "you know what you might write your essays for this module on. So one of you tell your partner, in one sentence, what your central argument is - then partners, come back with the first, most obvious criticism you can" - he drops his arms to guard his body - "and then I want you to work together to reframe the argument to counter that critique" - he throws a high, left hook. "Got it? Ok, off you go!" Chatter ensues, notes are taken - often at our encouragement - as students think through framing their theses in ways which pre-emptively address or neutralise potential counterpoints. A few minutes later we call the group to attention again, moving to the next phase of the lesson.

We now expand the physical metaphor to cover another element of academic writing that we often find students struggle with - transitioning between paragraphs. Alex tells the group - "so, me and Anastasiya are in a fight, ok? She's a boxer and I don't want to fight her standing up; I'm a decent wrestler and I want to try to strangle her! That's my best chance of winning. But I can't strangle her from here" - Alex puts his face to Anastasiya's outstretched fist - "so I need a way of getting from point A to point B, right? I need a transition." Together, the two execute a parry of a punch and two simple, controlled throwing moves. We have the group spread out and carefully rehearse this sequence, supervising the rudimentary take-down and arm-drag techniques. The students' enthusiasm is impossible to miss; laughter mixes with the exchange of feedback and congratulation as pairs of students learn to respond to each other's cues, timing their moves and rehearsing in collaboration, as we drift among them to correct and advise on their performance. 


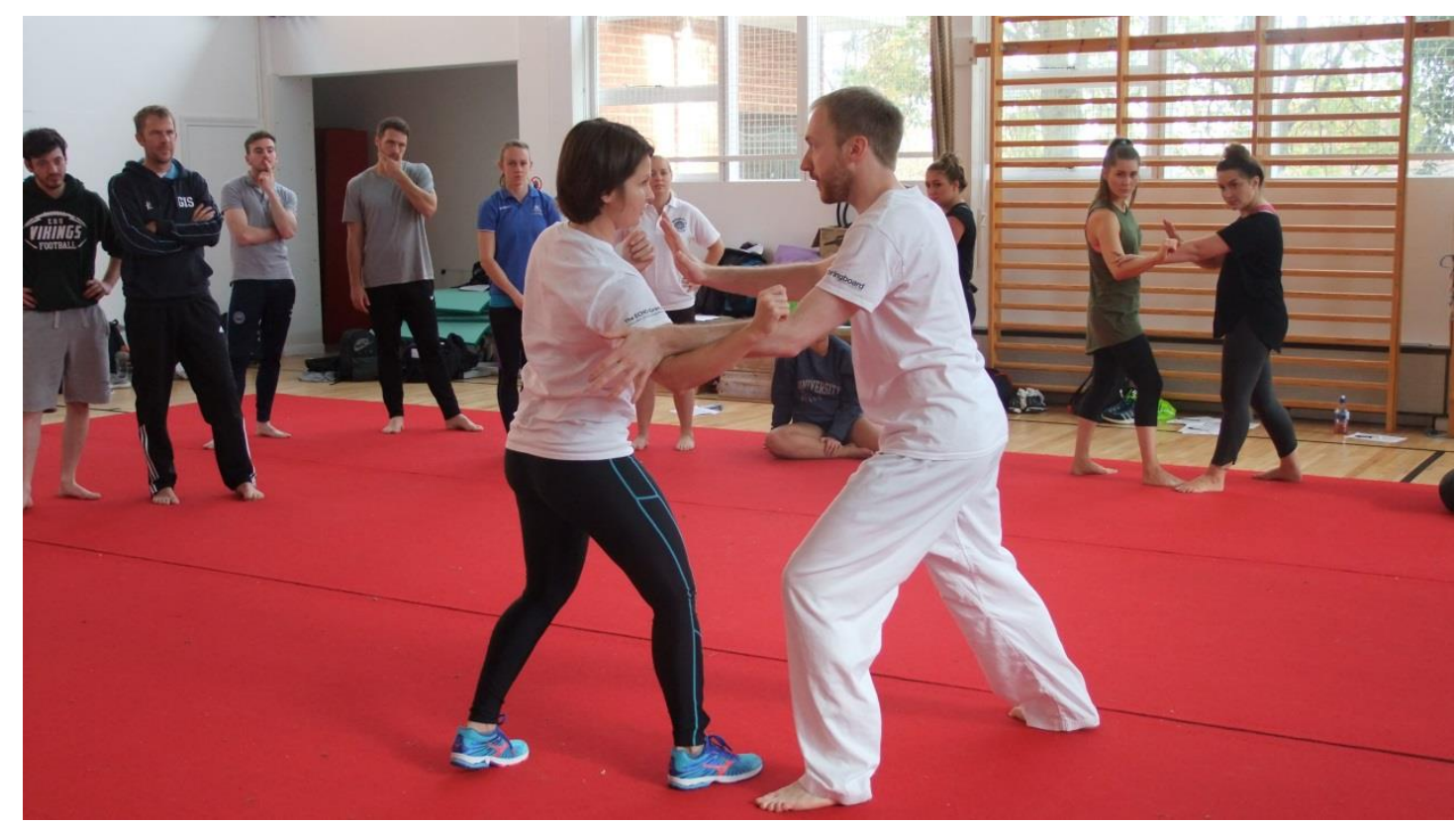

Fig.4 - Alex blocks Anastasiya's attack, setting up an arm-drag technique to move behind her and initiate a stranglehold. This mimics the importance of transitioning neatly and logically between disparate parts of a theoretical argument, moving one's reader along the journey towards a 'fightending', or argument-winning, conclusion. Photo courtesy of Gary Stidder.

"This is how you build your argument," Anastasiya says, as the group gathers around the television, a looped montage of mixed martial artists performing takedowns playing via YouTube. "You've made your first point, there's nothing more to gain by going on and on with it. You gotta get to the second point to close out the argument, to win the fight." The students collectively wince as a hard, slamming throw plays out on the screen. Alex continues the lesson: "Right! But you can't just suddenly start the next point. That fight didn't just suddenly drop to the ground - so when you change focus you need to get your reader there somehow." We then cut off the video, and each read out transitionary sentences from some of our own writing, explaining that even small segments of sentences can ease the flow of an academic argument. Then, handing out pre-prepared extracts of suitable journal articles that are relevant to the students' studies, we ask them to identify examples of good transitions themselves. After some time, they can easily identify and explain them back to us.

Such a lesson as this explores a metaphorical relationship that helps students understand the essentially interactional nature of writing. We highlight in these and other ways how writing can be imagined as part of a social encounter, conceivable in the context of a struggle between antagonists, namely the writer and their sceptical reader, whose resistance must be overcome through sound argument, backed by carefully-gathered evidence, skilfully delivered through logically structured, flowing prose. Students learn that they cannot simply write to evidence their own knowledge (i.e., shadow-box), but must do so directly and expressly in order to convince a reader of their point of view (i.e., actually hit a resisting opponent). The richness of the 'fighting' metaphor extends in various directions, and these hour-long sessions go by quickly, blending enjoyable (and for many students, wholly novel) physical activity with interactive learning and memorable video sequences. While this particular method for teaching writing resonates with us as a teaching team (we each train in combat sports and avidly follow boxing and mixed martial arts), it is also engaging for our 
students given its novelty value. Of course, this is but one of a range of possible ways to conceptualise writing as a social encounter that can be taught through the up-close and personal medium of embodied learning.

\section{Reflections and Conclusion}

While the use of movement in the classroom has enthused us and our students, and to date proven useful in diversifying and 'jazzing-up' (as one observing colleague put it) our classroom pedagogy, this method is not without its limitations. Principally, there is a duty of care here which lecturers must consider, concerning the need to ensure equity and prevent the isolation of those who cannot (or do not want to) engage in moving lessons. Simply put, our students do not move equally, and they do not all share the same physical abilities, which has clear implications for inclusivity when lessons are built around physical activity. However, because the model we are advocating here does not depend upon performing specific physical skills, and only really requires that students are in some way 'moving' while learning, this does not mean that physical disabilities (for instance) are an immovable barrier to their implementation. Rather, with an awareness of students' abilities beforehand, lecturers are able to shape classroom activities in ways which are as inclusive as possible while contributing to the intended learning outcomes of the session ${ }^{4}$.

Furthermore, it is entirely possible that differences in students' physical abilities can contribute to the potential for moving lessons to be useful pedagogical exercises. However, when making ability/disability salient to classroom learning, as with any such form of difference between students' own bodies, it is essential to retain a focus on preserving wellbeing while devising activities for use. Because students' ability ranges, along with any anxieties and vulnerabilities concerning their bodies and/or their abilities may not always be visible to lecturers (Kimball et al., 2016), it is vital to notify students in advance if a lesson is going to involve some kind of practical physical activity, and to make clear that they are not compulsory elements of that lesson. As noted previously, the examples listed here were delivered only after an initial period of teaching had passed, through which we were able to build rapport with the group in question and establish clear parameters regarding the moving lessons themselves, and the etiquette for engaging in them.

Another, more practical issue concerns fears over the health and safety implications of physical activity. The completion of risk assessments in line with local, institutional policies for specific, unusual teaching activities can be a source of frustration for colleagues wishing to use this sort of teaching method on a regular basis, while the actual risk posed by some activities, particularly if poorly supervised or practiced in unsuitable facilities, may itself prove a deterrent. While there are certainly important concerns, and may see some imagined exercises being necessarily discarded, we nevertheless argue that the potential payoff of moving lessons is worth taking a little time to assess and manage the risks associated with them.

This said, we nevertheless appreciate that for some groups of students and some topical foci, physical activities may prove difficult to execute in ways which effectively prove inclusive, non-

4 The literature on 'adapted physical activity', again derived from the physical education field, is worth consulting here. See for instance Sherrill (2004). 
threatening, safe, and pedagogically worthwhile. Indeed, the simple matter of being confident that conceptual material will be made clearer by a moving lesson is perhaps one of the most obvious problems facing the implementation of such exercises, as too is the question of whether students will indeed benefit from them in the ways we've suggested they can. Certainly we have met with some instances of physical activities 'falling flat', most often due to poor planning on our part which left students under-engaged in exercises that seemed particularly useful in theory. As such, there is inevitably an element of risk-taking, and some trial-and-error, involved with making moving lessons a useful and meaningful addition to lecturers' pedagogical repertoires. Any colleagues interested in adopting this technique for the first time would do well to be mindful of the likely realities of initial failures.

Despite these drawbacks though, when engaging our students in the manner outlined above we have gained reportedly fantastic results in terms of learning, engagement and satisfaction. For instance, formal student feedback on the modules within which we have used these methods has been consistently improved from previous years, most notably with respect to items concerning the enjoyment of learning and quality of teaching. Perhaps more importantly though, we have used these exercises to help break down preconceptions about sociological theory and what studying sociology actually entails, inviting our students to experience a different way of exploring important academic ideas and ultimately, help shape their sociological imaginations in novel and memorable ways.

As such, it is our contention that learning by moving imbues the taught curriculum with a kind of vitality and personal significance that more abstract methods are not as able to achieve. The recognition that students live their lives as embodied subjects, with a capacity to learn that extends beyond audio-visual communication and into the realm of bodily movement, can provide lecturers with a valuable resource for personalising learning and fostering student engagement. We hope that the brief discussion and selected examples included in this chapter are of use to any colleagues who wish to develop their use of similar classroom methods.

\section{Suggested Discussion Questions}

1. How could physical exercises, games, dances or other forms of movement become 'physical metaphors' useful for teaching theoretical or practical topics within your subject area?

2. Which forms of movement might best resonate with the interests of the students you are currently teaching, or enthuse them the most?

3. How might you adapt familiar movement forms (for instance, by blindfolding some students, changing games' rules, etc.) to make them more pedagogically effective in the context of the lesson you use them for?

4. What limitations will you need to consider in order to ensure that 'moving lessons' are as inclusive as possible for all the students you teach?

\section{References}

Biggs, J. and Tang, C. (2011) Teaching for Quality Learning at University ( $4^{\text {th }}$ edition). Maidenhead: Open University Press. 
Brockbank, A. and McGill, I. (2007) Facilitating Reflective Learning in Higher Education (2 ${ }^{\text {nd }}$ edition). Maidenhead: Open University Press.

Cromby, J. (2015) Feeling Bodies: Embodying Psychology. Basingstoke: Palgrave Macmillan.

Crossley, N. (2006) Reflexive Embodiment in Contemporary Society. Maidenhead: Open University Press.

Dunn, R. and Dunn, K. (1992) Teaching Secondary Students through their Individual Learning Styles. Needham Heights, MA: Allyn and Bacon.

Dunne, E. and Owen, D. (eds.) (2013) The Student Engagement Handbook: Practice in Higher Education. Bingley: Emerald.

Fry, H., Ketteridge, S. and Marshall, S. (eds.) (2015) A Handbook for Teaching and Learning in Higher Education: Enhancing Academic Practice (4 ${ }^{\text {th }}$ edition). Abingdon: Routledge.

Gardner, H. (2006) Multiple Intelligences: New Horizons. New York, NY: Basic Books.

Green, K. (2008) Understanding Physical Education. London: SAGE.

Hardman, K. and Green, K. (2011) (eds.) Contemporary Issues in Physical Education. Maidenhead:

Meyer \& Meyer Sport.

Kimball, E.W., Wells, R.S., Ostiguy, B.J., Manly, C.A. and Lauterbach, A.A. (2016) Students with disabilities in higher education: A review of the literature and an agenda for future research. In M.B. Paulsen (ed.) Higher Education: Handbook of Theory and Research, volume 31. Switzerland: Springer. Kolb, D. (1984) Experiential Learning. Englewoods Cliffs, NJ: Prentice Hall.

Lea, J. (ed.) (2015) Enhancing Learning and Teaching in Higher Education: Engaging with the Dimensions of Practice. Maidenhead: Open University Press

Light, G., Cox, R. and Calkins, S. (2009) Learning and Teaching in Higher Education: The Reflective Professional. London: SAGE.

Mortiboys, A. (2010) How to be an Effective Teacher in Higher Education. Maidenhead: Open University Press.

Shapiro, L. (ed.) (2014) The Routledge Handbook of Embodied Cognition. London: Routledge.

Sherrill, C. (2004) Adapted Physical Activity, Recreation, and Sport: Crossdisciplinary and Lifespan (6 $6^{\text {th }}$ edition). London, McGraw-Hill.

Spatz, B. (2015) What a Body Can Do: Theory as Knowledge, Practice as Research. Abingdon:

Routledge. 